\title{
Spatial and temporal variability of soil electrical conductivity related to soil moisture
}

José Paulo Molin ${ }^{*}$, Gustavo Di Chiacchio Faulin²

1USP/ESALQ - Depto. de Engenharia de Biossistemas, Av. Pádua Dias, 11 - 13418-900 - Piracicaba, SP - Brasil. 2FATEC Marilia, Campus de Pompéia, Av. Shunji Nishimura, 605 - 17580-000 - Pompéia, SP - Brasil.

${ }^{*}$ Corresponding author <jpmolin@usp.br>

Edited by: José Euclides Stipp Paterniani

Received September 22, 2011

Accepted August 23, 2012
ABSTRACT: Soil electrical conductivity $(\mathrm{EC}$ a) is a soil quality indicator associated to attributes interesting to site-specific soil management such as soil moisture and texture. Soil ECa provides information that helps guide soil management decisions, so we performed spatial evaluation of soil moisture in two experimental fields in two consecutive years and modeled its influence on soil ECa. Soil ECa, moisture and clay content were evaluated by statistical, geostatistical and regression analyses. Semivariogram models, adjusted for soil moisture, had strong spatial dependence, but the relationship between soil moisture and soil ECa was obtained only in one of the experimental fields, where soil moisture and clay content range was higher. In this same field, coefficients of determinations between soil moisture and clay content were above 0.70 . In the second field, the low soil moisture and clay content range explain the absence of a relationship between soil ECa and soil moisture. Data repetition over the years, suggested that ECa is a qualitative indicator in areas with high spatial variability in soil texture.

Keywords: precision agriculture, soil physics, geostatistics, soil sensors

\section{Introduction}

Soil electrical conductivity (ECa) is an effective and rapid indicator of soil variability and production potential (Corwin et al., 2003; Corwin and Lesch, 2005). This is associated to soil attributes interesting to precision agriculture.

Electrical conductivity can be defined as the ability of a material to transmit or conduct electrical current. This is the case of soil, which can conduct an electrical current through electrolytes dissolved in soil solution (water) and through exchangeable cations close to charged particle surfaces and electrically mobile at a number of levels. An ECa model developed by Rhoades and Corwin (1990) describes three conduction pathways: (i) between alternate layers of soil particles and soil solution, (ii) through continuum soil solutions, and (iii) through or between soil particle surfaces directly in contact with each other. Therefore, in addition to soil moisture content, ECa is associated to soil salinity, clay content and cation exchange capacity, clay minerals, pore size and distribution, organic matter and temperature (Mcneill, 1992; Sudduth et al., 2001). ECa was also shown to indicate soil texture variability, i.e., ECa is higher in soils with high clay content and lower in soils with high sand content (Machado et al., 2006; Molin and Castro, 2008; Moral et al., 2010; Aimrun et al., 2011). Other authors have investigated the relationship between soil moisture and ECa (Sheets and Hendrickx, 1995) and ECa has been used for defining management zones taking water as the limiting factor (Besson et al., 2010).

Commercial devices for rapid ECa determination provide useful information for decision-making in crop management (Siri-Prieto et al., 2006). However, the quality of ECa information on Brazilian soils is poor. This information is important for tropical agricultural soils, especially because they usually have low levels of dissolved salts. Since ECa, texture and moisture are expected to be correlated, the objective of this study was to perform spatial monitoring of soil moisture in two different experimental fields over two consecutive years and evaluate the influence of moisture on soil ECa. The results provide new insight on the interpretation of ECa information for tropical soils and on its relationship with soil moisture.

\section{Materials and Methods}

This study was carried out in two experimental fields. Field 1, in Tibagi, state of Paraná (PR), Brazil $\left(24^{\circ} 32^{\prime} \mathrm{S} 50^{\circ} 21^{\prime} \mathrm{W}\right)$, covers 18.9 ha, with a mean altitude of $826 \mathrm{~m}$ and predominance of medium-textured Typic Dystrudoxes with moderate A horizon. Field 2, in Campos Novos Paulista, state of São Paulo (SP), Brazil (22 $\left.41^{\prime} \mathrm{S} 49^{\circ} 59^{\prime} \mathrm{W}\right)$, covers 22.2 ha, with a mean altitude of $533 \mathrm{~m}$, and predominance of medium-textured Typic Hapludoxes with moderate A horizon, both representative of two major grain production regions in the South/Southeast of Brazil.

Soil ECa was measured with a direct-contact sensor (Veris 3100, Veris Technologies, Inc., Salina, KS, USA) connected to a GPS receiver that provided the exact location of each reading. Gebbers et al. (2009) evaluated seven instruments for geoelectrical soil mapping at the field scale and considered it one of the most suitable instruments for precision agriculture applications. The sensor was passed along parallel lines through the fields, forming $10.0 \mathrm{~m}$ wide swaths. The sensor uses three pairs of flat cutting discs with a diameter of $0.43 \mathrm{~m}$ that serve as electrodes with direct soil contact; one pair applies electrical current into the soil and the other two pair of discs measure the voltage drop between them. The electrodes are inserted a few centimeters into the soil to ensure electrical contact. Spacing between emitter and receiver electrodes deter- 
mines the thickness of soil this device reads, which can be concentrated approximately at $0.3 \mathrm{~m}$ or $0.9 \mathrm{~m}$. In this study, only the shallowest soil portion $(0.3 \mathrm{~m})$ was evaluated as the soil on both fields has no substantial vertical stratification and both fields have been farmed under no-till for several years, with few anthropic interventions in the soil profile. Field 1 was studied in Oct. 2003 and Jun. 2004, while Field 2 in Oct. 2003 and Oct. 2004.

While the sensor was pulled over the fields, simple soil samples were collected and georeferenced to determine moisture content in the $0.3 \mathrm{~m}$ depth using a helicoidal auger. The samples were kept in aluminum capsules, sealed and taken to the laboratory. Samples were weighed, oven dried at $105^{\circ} \mathrm{C}$ until mass stabilization and weighed again for gravimetric soil moisture content to be determined. Five sub-samples were collected to determine soil texture, within a $5 \mathrm{~m}$ radius of the georeferenced sampling site, which in turn were positioned in a sampling grid. In Field 1 soil samples were removed at 0-0.2 m depth using a helicoidal auger in 2003; in Field 2 , soil samples were available from earlier studies at this site. Bouyoucos's or densimetric method (Bouyoucos, 1962) was used to determine texture.

Statistica 6.0 software was used for exploratory analyses. We calculated until the fourth-order statistical moment to characterize data behavior. Variability was determined by the coefficient of variation $(\mathrm{CV})$, which was categorized as low $(\mathrm{CV}<12 \%)$, moderate $(12<\mathrm{CV}<62 \%)$ or high $(\mathrm{CV}>62 \%)$ (Warrick and Nielsen, 1980). A second stage of this analysis was performed to validate or not apparently discrepant data. This was achieved by combining exploratory analyses with a spatial description of the variable sets obtained. Despite the high quality of statistical analyses, they disregard the spatial position of each sample. Spatialization of apparently discrepant ECa results and soil moisture and clay content were performed using a geographic information system (GIS) (SSToolBox 3.4, SST Development Group, Stillwater, OK, USA). If these values were clustered, they were not considered discrepant or excluded from analyses.

Vesper 1.6 software (ACPA, University of Sydney) was used to calculate experimental $\mathrm{ECa}$, soil moisture and clay content semivariograms of both experimental fields. Semivariograms were obtained using a classical Matheron semivariogram estimator and fit to the experimental semivariograms obtained. Those with the best fit in terms of sum of squared residuals (SSR) were selected. The classification proposed by Cambardella et al. (1994) was used to determine the dependence level of the studied attributes. Spatial dependence is therefore strong in semivariograms with a nugget effect $\left(\mathrm{C}_{0}\right)$ less than or equal to $25 \%$ of the sill, moderate between $25 \%$ and $75 \%$ and weak above $75 \%$.

After spatial dependence analyses, we evaluated sites that had not been sampled in order to produce surface maps by ordinary block kriging. This was achieved using the Vesper 1.6 software, which generates raster maps with $10 \times 10 \mathrm{~m}$ pixels. The range of kriged dataset for moisture and clay content corresponded to the spatial continuity of each of these variables. With respect to ECa, which had higher sampling density compared to the other variables, Vesper 1.6 determined the searching range without researcher interference.

Regression analysis was used to evaluate the interdependence of the studied attributes. ECa, moisture and clay content values were interpolated and then regressions were performed to obtain the coefficients of determination $\left(\mathrm{R}^{2}\right)$.

\section{Results and Discussion}

The attributes studied had similar mean and median values, although medians were, in general, lower and some asymmetrical distributions were observed (Table 1), indicating that abnormally distributed data does not affect the measures of central tendency (Cambardella et al, 1994). Field 2 had lower attribute variation than Field 1. According to the classification proposed by Warrick

Table 1 - Exploratory statistics for soil electrical conductivity (ECa), moisture and clay content.

\begin{tabular}{|c|c|c|c|c|c|c|c|c|c|c|c|}
\hline \multirow{2}{*}{ Year } & \multirow{2}{*}{ Variable } & \multicolumn{2}{|c|}{ Number of points ${ }^{1}$} & \multirow[b]{2}{*}{ Mean } & \multirow{2}{*}{ Median } & \multirow{2}{*}{ Min. } & \multirow{2}{*}{ Max. } & \multirow{2}{*}{$\mathrm{SD}^{2}$} & \multirow{2}{*}{$\mathrm{CV}^{3}$} & \multirow{2}{*}{ Asym. ${ }^{4}$} & \multirow{2}{*}{ Kurt. $^{5}$} \\
\hline & & Initial & Final & & & & & & & & \\
\hline & & & & & Field 1 & & & & & & \\
\hline \multirow[t]{2}{*}{2003} & $\mathrm{ECa}\left(\mathrm{mS} \mathrm{m}^{-1}\right)$ & 5004 & 5003 & 4.1 & 3.6 & 1.0 & 12.9 & 1.8 & 43.5 & 0.86 & 0.28 \\
\hline & Moisture (\%) & 83 & 83 & 16.2 & 14.8 & 10.3 & 27.6 & 4.6 & 28.6 & 0.78 & -0.37 \\
\hline \multirow[t]{3}{*}{2004} & $\mathrm{ECa}\left(\mathrm{mS} \mathrm{m}^{-1}\right)$ & 8472 & 8472 & 3.0 & 2.4 & 0.6 & 13.1 & 1.7 & 57.4 & 1.08 & 0.92 \\
\hline & Moisture (\%) & 84 & 84 & 15.6 & 14.2 & 9.2 & 26.6 & 4.8 & 30.5 & 0.68 & -0.60 \\
\hline & Clay (\%) & 42 & 42 & 21.5 & 18.9 & 11.5 & 42.3 & 9.1 & 42.5 & 0.90 & -0.45 \\
\hline \multicolumn{12}{|c|}{ Field 2} \\
\hline \multirow[t]{2}{*}{03} & $\mathrm{ECa}\left(\mathrm{mS} \mathrm{m}^{-1}\right)$ & 10402 & 10388 & 6.2 & 6.1 & 2.9 & 16.6 & 1.3 & 21.5 & 0.70 & 1.70 \\
\hline & Moisture (\%) & 63 & 63 & 12.4 & 12.3 & 9.5 & 14.5 & 1.3 & 10.8 & -0.46 & -0.65 \\
\hline \multirow[t]{3}{*}{04} & $\mathrm{ECa}\left(\mathrm{mS} \mathrm{m}^{-1}\right)$ & 8734 & 8529 & 8.3 & 8.2 & 3.9 & 12.7 & 1.7 & 20.2 & 0.16 & -0.12 \\
\hline & Moisture (\%) & 33 & 32 & 12.2 & 12.1 & 10.1 & 13.6 & 0.9 & 7.3 & -0.27 & -0.32 \\
\hline & Clay (\%) & 92 & 92 & 23.1 & 23.0 & 16.1 & 36.2 & 3.7 & 15.9 & 0.80 & 1.48 \\
\hline
\end{tabular}

${ }^{1}$ Before and after removing the outlier data identified by exploratory analyses; ${ }^{2}$ standard deviation; ${ }^{3}$ Coefficient of variation; ${ }^{4}$ asymmetry; ${ }^{5}$ kurtosis. 
and Nielsen (1980), CVs in Field 1 can be considered moderate, whereas in Field 2 they were low for moisture content and moderate for soil ECa and clay content. Corwin et al. (2003) and Corwin and Lesch (2005) found similar CV values of those from Field 1 (43\% and $57 \%$ for the first and second year, respectively) in North American soils and considered the $\mathrm{CV}$ as a first indicator of the possible relevant spatial variability. At this level of variability, ECa may serve as an indicator of soil quality, and it requires further investigation. Field 2 ECa was similar on both years (around 20\%) limited by the lower spatial variability of clay content and, in consequence, by soil moisture. In this case, the scale of the investigation may be affecting the results.

Table 2 shows semivariogram models and parameters. The attributes were fitted to the spherical model over a two-year period, except for soil ECa in Field 2, which was fitted to the exponential model. Spherical mathematical models prevail in soil science studies (Carvalho et al., 2002). However, Siri-Prieto et al. (2006) and Molin and Castro (2008) fitted soil ECa to exponential models.

According to the spatial dependence degree, the attributes studied had moderate to strong spatial dependence (Table 2), showing that their spatial distribution was not randomized (Cambardella et al., 1994). In Field 1, spatial dependence explains $95.4 \%$ of total ECa variation in 2003 and $94.9 \%$ in 2004, with random error caused by a nugget effect of $4.6 \%$ and $5.1 \%$, respectively. In Field 2, random errors in ECa were 62.8 $\%$ in 2003 and $46.5 \%$ in 2004. These errors are associated to lower spatial dependence of ECa variation in Field 2 compared to Field 1 . The difference is related to the spatial distribution of the dominant factors affecting ECa on both fields.

Range can be defined as the maximum distance (radius) allowed for sampling continuous paths for kriging interpolation. ECa range in Field 2 was $24.5 \mathrm{~m}$ in 2003 and $21.2 \mathrm{~m}$ in 2004, corresponding to $18 \%$ and $15 \%$ of the values obtained in Field 1, respectively. The use of narrow ranges may compromise model predictions due to the reduced number of interpolation points. Nevertheless, the kriging interpolation used to estimate ECa in Field 2 exhibited good quality for practical purposes because of the high sampling density performed by the equipment used. The results obtained reinforce the higher spatial distribution discontinuity of ECa in Field 2.

Semivariogram model parameters combined with kriging technique estimated attribute values in areas not sampled. The magnitude of the nugget effect is important for kriging because the higher its difference for the semivariogram sill, the higher the phenomenon continuity, the lower the estimation variance, or the higher the estimation confidence. With the maps from kriging (not shown) the regressions were obtained and Table 3 shows $\mathrm{R}^{2}$ values from regression analyses between ECa and soil moisture and clay levels. Significant regressions were observed (F test, $p<0.01)$ except for clay content in Field 2 in 2004 (F test, $p>0.1$ ). Even though, in a very low rate clay and moisture content had an effect on ECa also on field 2.

The coefficient of determination $\left(\mathrm{R}^{2}\right)$ between soil ECa and clay content in Field 1 was similar to those reported in earlier studies, where $\mathrm{R}^{2}$ values ranged from 0.50 (Johnson et al., 2001) to 0.76 (Corwin et al., 2003). Regression analyzes between soil ECa and moisture level in Field 1 was 0.73 in 2003 and 0.74 in 2004. Moral et al. (2010) used the same equipment as in this study to measure soil ECa and found that clay presented positive high correlation and coarse sand and fine sand exhibited negatively high correlation, particularly with ECa at the shallowest soil portion $(0.3 \mathrm{~m})$ of a soil in a field test in Spain.

Table 3 - Regression analyses between soil electrical conductivity (ECa) and soil moisture and clay levels.

\begin{tabular}{|c|c|c|c|c|c|c|}
\hline & \multirow{2}{*}{ Field } & \multirow{2}{*}{ Year } & \multicolumn{2}{|c|}{ Moisture level } & \multicolumn{2}{|c|}{ Clay level } \\
\hline & & & $\mathrm{R}^{2}$ & $\mathrm{~F}$ & $\mathrm{R}^{2}$ & $\mathrm{~F}$ \\
\hline \multirow{4}{*}{$\mathrm{ECa}$} & \multirow{2}{*}{1} & 2003 & 0.7725 & $*$ & 0.7318 & * \\
\hline & & 2004 & 0.7421 & * & 0.7158 & * \\
\hline & \multirow{2}{*}{2} & 2003 & 0.0386 & * & 0.0013 & * \\
\hline & & 2004 & 0.0893 & * & 0.0000 & ns \\
\hline
\end{tabular}

${ }^{*} \mathrm{~F}$ test, significant at $p<0.01 ; \mathrm{ns}=\mathrm{F}$ test, non-significant $(p>0.01)$.

Table 2 - Semivariogram models and parameters fitted to the soil attributes studied.

\begin{tabular}{|c|c|c|c|c|c|c|c|c|}
\hline Year & Attribute & Model & $\mathrm{C}_{0}{ }^{3}$ & Sill & $\mathrm{R}(\mathrm{m})^{4}$ & DR $(\%)^{5}$ & $\mathrm{SDD}^{6}$ & $\mathrm{RSS}^{7}$ \\
\hline \multicolumn{9}{|c|}{ Field 1} \\
\hline \multirow{2}{*}{2003} & $\mathrm{ECa}$ & Sph. ${ }^{1}$ & 0.1352 & 2.9402 & 135.9 & 4.60 & Strong & $8.69 \mathrm{E}-03$ \\
\hline & Moisture & Sph. ${ }^{1}$ & 0.0001 & 0.0633 & 168.7 & 0.16 & Strong & $6.71 \mathrm{E}-05$ \\
\hline \multirow{3}{*}{2004} & $\mathrm{ECa}$ & Sph. ${ }^{1}$ & 0.1358 & 2.6778 & 140.8 & 5.07 & Strong & $3.00 \mathrm{E}-02$ \\
\hline & Moisture & Sph. ${ }^{1}$ & 0.0090 & 19.3800 & 148.9 & 0.05 & Strong & 30.76 \\
\hline & Clay & Sph. ${ }^{1}$ & 0.0002 & 0.1509 & 153.0 & 0.13 & Strong & 1.17E-03 \\
\hline \multicolumn{9}{|c|}{ Field 2} \\
\hline \multirow{2}{*}{2003} & Eca & $\operatorname{Exp}^{2}$ & 0.8284 & 1.3195 & 24.5 & 62.79 & Mod. ${ }^{8}$ & 6.83E-04 \\
\hline & Moisture & Sph. ${ }^{1}$ & 0.0001 & 0.0122 & 185.4 & 0.83 & Strong & 9.16E-05 \\
\hline \multirow{3}{*}{2004} & Eca & Exp. $^{2}$ & 0.6555 & 1.4109 & 21.2 & 46.47 & Mod. ${ }^{8}$ & 6.79E-03 \\
\hline & Moisture & Sph. ${ }^{1}$ & 0.0003 & 0.0062 & 361.1 & 4.76 & Strong & 2.20E-06 \\
\hline & Clay & Sph.1 & 0.0122 & 0.0240 & 307.3 & 50.41 & Mod. 8 & 3.19E-05 \\
\hline
\end{tabular}

${ }^{1}$ Spherical; ${ }^{2}$ exponential; ${ }^{3}$ nugget effect; ${ }^{4}$ range (m); ${ }^{5}$ dependence ratio; ${ }^{6}$ spatial dependence degree; ${ }^{7}$ residual sum of squares; ${ }^{8}$ moderate. 
An important result was reading repetition over the two years. The fact that ECa reading varied as a function of soil moisture at reading time suggests that it is a good soil quality indicator that is magnified by moisture level, which in turn depends on soil texture, as also indicated by the work of Gebbers et al. (2009) and Aimrun et al. (2011).

In Field 2, $\mathrm{R}^{2}$ was close to zero between ECa and soil moisture and null between ECa and clay content, indicating the weak or even absent relationship between ECa and these variables. The expected attribute relationships were not obtained in Field 2, likely because it had lower clay and moisture ranges than Field 1, i.e., lower spatial variability of the attributes, illustrated by lower spatial dependence. The different results indicate that may have a threshold of range for clay and moisture in the soil where ECa can be used to express it and more studies are required to model it with more detail.

The relationships between the attributes were well evidenced in Field 1. In this case, soil ECa can be used to delineate management zones as a function of soil clay content. This was indeed highly related with moisture levels in $2003\left(\mathrm{R}^{2}=0.93, p<0.0001\right)$ and $2004\left(\mathrm{R}^{2}=0.92, p<0.0001\right)$. Field 2 presented the respective $\mathrm{R}^{2}$ values of 0.36 and 0.65 ( $\left.p<0.0001\right)$. Soil ECa reading depends on soil texture and moisture availability, which are spatially variable attributes that may further affect productivity.

\section{Conclusions}

Relationship between moisture and ECa was found only in experimental Field 1, which had a higher soil moisture range. In this same area, the coefficients of determination between ECa and moisture and clay content were higher than $72 \%$. The expected attribute relationships were not obtained in Field 2, likely because it had lower clay and moisture ranges than Field 1 with lower spatial variability of the attributes, illustrated by lower spatial dependence. ECa is a qualitative indicator in areas with high spatial variability in soil texture. In Field 2, where soil moisture range was lower, ECa was not associated to moisture levels.

\section{Acknowledgements}

This study was sponsored by FAPESP, CNPq and Fundação $A B C$ and received logistical support from experimental field owners.

\section{References}

Aimrun, W.; Amin, M.S.M.; Nouri, H. 2011. Paddy field zone characterization using apparent electrical conductivity for rice precision farming. International Journal of Agricultural Research 6: 10-28.
Besson, A.; Cousin, I.; Bourennane, H.; Nicollaud, C.; Pasquier, C.; Richard, G. 2010. The spatial and temporal organization of soil water at the field scale as described by electrical resistivity measurements. European Journal of Soil Science 61: $120-132$.

Bouyoucos , G. J. 1962. Hydrometer method improved for making particle size analysis of soils. Agronomy Journal 54:464-465.

Cambardella, C.A.; Moorman, T.B.; Novark, J.M.; Parkin, T.B.; Karlen, D.L.; Turco, R.F.; Konopka, A.E. 1994. Field-scale variability of soil properties in central Iowa soils. Soil

Science Society of America Journal 58: 1501-1511.

Carvalho, J.R.P.D.; Silveira, P.M.; Vieira, S.R. 2002. Geostatistics to determine spatial variability of soil chemical properties using different preparation systems. Pesquisa Agropecuária Brasileira 37: 1151-1159 (in Portuguese, with abstract in English).

Corwin, D.L.; Lesch, S.M.; Shouse, P.J.; Soppe, R.; Ayars, J.E. 2003. Identifying soil properties that influence cotton yield using soil sampling directed by apparent soil electrical conductivity. Agronomy Journal 95: 352-364.

Corwin, D.L.; Lesch, S.M. 2005. Characterizing soil spatial variability with apparent soil electrical conductivity. Part II. Case study. Computers and Electronics in Agriculture 46: 135-152.

Johnson, C.K.; Doran, J.;Duke, H.R.; Wienhold, B.J.; Eskridge, K.; Shanahan, J.F. 2001. Field-scale electrical conductivity mapping for delineating soil condition. Soil Science Society of America Journal 65: 1829-1837.

Empresa Brasileira de Pesquisa Agropecuária [Embrapa]. 1997. Sistema Agroindustrial do Leite no Brasil = Dairy Agriindustrial System in Brazil. Embrapa Solos: Rio de Janeiro, RJ, Brazil.

Gebbers, R.; Lück, E.; Dabas, M.; Domsch, H. 2009. Comparison of instruments for geoelectrical soil mapping at the field scale. Near Surface Geophysic 7: 179-190.

Machado, P.L.O.A.; Bernardi, A.C.C.; Valencia, L.I.O.; Molin, J.P.; Gimenez, L.M.; Silva, C.A.; Andrade, A.G.A.; Madari, B.E., Meirelles, M.S.P.M. 2006. Electrical conductivity mapping in relation to clay of a Ferralsol under no tillage system. Pesquisa Agropecuária Brasileira 41: 1023-1031 (in Portuguese, with abstract in English).

Molin, J.P.; Castro, C.N.D. 2008. Establishing management zones using soil electrical conductivity and other soil properties by the fuzzy clustering technique. Scientia Agricola 65: 567-573.

Moral, F.J.; Terrón, J.M.; Marques da Silva, J.R. 2010. Delineation of management zones using mobile measurements of soil apparent electrical conductivity and multivariate geostatistical techniques. Soil and Tillage Research 106: 335343.

Rhoades, J.D.; Corwin, D.L. 1990. Soil electrical conductivity: effects of soil properties and application to soil salinity appraisal. Communications in Soil Science Plant Analysis 21: 837-860.

Sheets, K.R.; Hendrickx, J.M.H. 1995. Noninvasive soil water content measurement using electromagnetic induction. Water Resources Research 31: 2401-2409. 
Siri-Prieto, G.; Reeves, D.W.; Shaw, J.N.; Mitchell, C.C. 2006. World's oldest cotton experiment: relationships between soil chemical and physical properties and apparent electrical conductivity. Communications in Soil Science Plant Analysis 37: 767-786.

Sudduth, K.A.; Drummond, S.T.; Kitchen, N.R. 2001. Accuracy issues in electromagnetic induction sensing of soil electrical conductivity for precision agriculture. Computers and Electronics in Agriculture 31: 239-264.
Warrick, A.W.; Nielsen, D.R. 1980. Spatial variability of soil physical properties in the field. p. 319-44. In: Hillel, D. (Ed.). Applications of Soil Physics. Academic Press, New York, NY, USA. 